
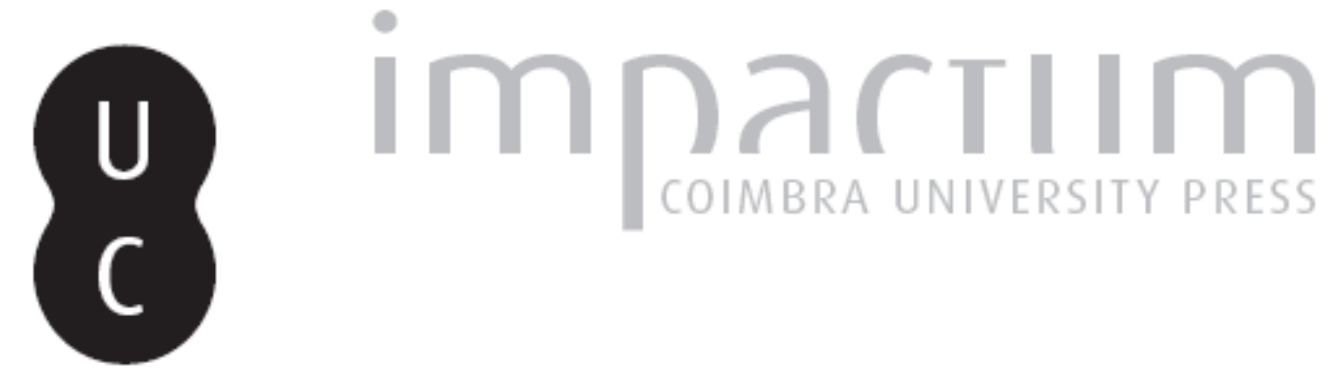

\title{
Diversidade e serviço público de televisão no contexto regulatório português
}

Autor(es): Cádima, Francisco Rui

Publicado por: Imprensa da Universidade de Coimbra

URL persistente:

URl:http://hdl.handle.net/10316.2/43224

DOI:

DOI:https://doi.org/10.14195/2183-5462_31_2

Accessed : $\quad$ 26-Apr-2023 09:48:20

A navegação consulta e descarregamento dos títulos inseridos nas Bibliotecas Digitais UC Digitalis, UC Pombalina e UC Impactum, pressupõem a aceitação plena e sem reservas dos Termos e Condições de Uso destas Bibliotecas Digitais, disponíveis em https://digitalis.uc.pt/pt-pt/termos.

Conforme exposto nos referidos Termos e Condições de Uso, o descarregamento de títulos de acesso restrito requer uma licença válida de autorização devendo o utilizador aceder ao(s) documento(s) a partir de um endereço de IP da instituição detentora da supramencionada licença.

Ao utilizador é apenas permitido o descarregamento para uso pessoal, pelo que o emprego do(s) título(s) descarregado(s) para outro fim, designadamente comercial, carece de autorização do respetivo autor ou editor da obra.

Na medida em que todas as obras da UC Digitalis se encontram protegidas pelo Código do Direito de Autor e Direitos Conexos e demais legislação aplicável, toda a cópia, parcial ou total, deste documento, nos casos em que é legalmente admitida, deverá conter ou fazer-se acompanhar por este aviso.

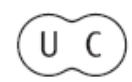




\section{Media Jornalismo}

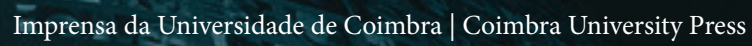

N. 31 Vol. 17, N. ${ }^{\circ} 2$ - 2017

Esia

(2) M MEDIA E DIVERSIDADE

लिखिएक

2)

*).

() (6) $3(9)$

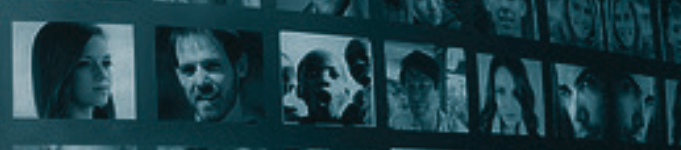

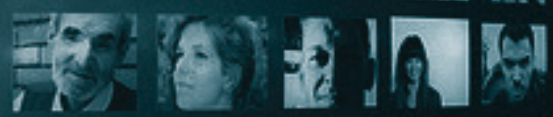

* a

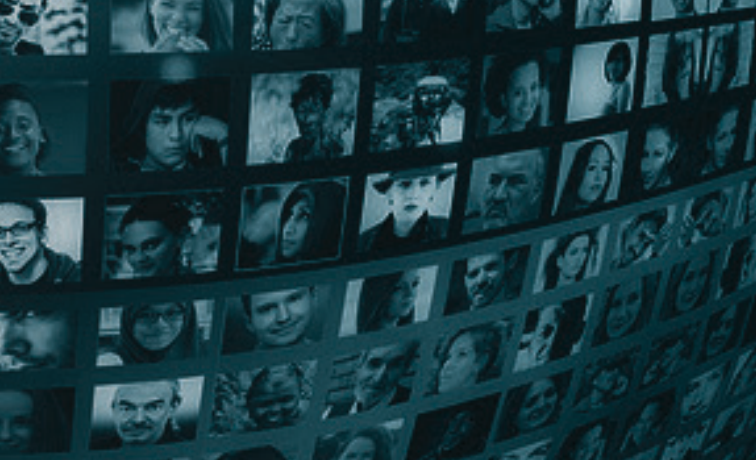

तथ 


\title{
DIVERSIDADE E SERVIÇO PÚBLICO DE TELEVISÃO NO CON- TEXTO REGULATÓRIO PORTUGUÊS
}

\author{
DIVERSITY AND PUBLIC SERVICE BROADCASTING IN THE \\ CONTEXT OF REGULATION: THE PORTUGUESE CASE
}

\section{FRANCISCO RUI CÁDIMA}

Universidade Nova de Lisboa. Faculdade de Ciências Sociais e Humanas. Centro de Investigação em ComunicaÇão, Informação e Cultura Digital (CiC. Digital FCSh/NOVA), 1069-061 Lisboa, Portugal

frcadima@fcsh.unl.pt

\section{Resumo}

Diversidade e pluralismo são hoje conceitos e práticas que devem ser particularmente protegidos no atual ecossistema mediático e digital, sob pena de, com a sua diluição, se estar a liquefazer a própria experiência democrática, abrindo-se assim mais facilmente 0 caminho aos populismos e totalitarismos. Estas ameaças estão agora a espreitar as fragilidades da experiência democrática europeia do pós-guerra, numa Europa profundamente debilitada num contexto de globalização perversa e de ausência de coesão e de mediação de solidariedades a que chegámos na União Europeia. Este texto procura fazer um ponto de situação relativamente à regulação dos conteúdos de media no caso português, procurando sistematizar em particular o modo como a questão da diversidade, no contexto do Serviço Público de Televisão (SPT), tem sido monitorizada em Portugal.

\section{Palavras-chave:}

Media; Diversidade; Pluralismo; ERC; Serviço Público de Televisão

\section{Abstract}

Diversity and pluralism are concepts and practices that must be particularly protected in the current media and digital ecosystem; otherwise, with their dilution, the own democratic experience may be liquefied, thus opening the way to populism and totalitarianism. These threats are now looking at the weaknesses of post-war European democratic experience, in a Europe that has been profoundly weakened by the context of perverse globalization, lack of cohesion and of mediation of solidarities that currently characterize the European Union. This text tries to analyse the current situation regarding the regulation of media content in the Portuguese case, seeking to particularly systematize how the issue of diversity has been monitored in Portugal with regard to Public Service Broadcasting.

KEYWORDS:

Media; Diversity; Pluralism; ERC; Public Service Broadcasting 
INTRODUÇÃO

Estamos a entrar agora numa complexa era em que os algoritmos "assumem 0 comando". Vai longe o tempo em que essa competência pertenceu à mecanização, como Siegfried Giedion descreveu, ou à eletrónica, como McLuhan problematizou. Mas tudo mudou nesta recente vertigem atual despoletada pelas máquinas informacionais. Os novos "gatekeepers", ou "bots", robots, hoje não olham à diversidade ou à diferenciação das vozes, preferem antes a "economia dos clicks", ou a organização da informação segundo o princípio do "the winner takes it all", ou seja, colocando no ranking dos motores de busca as "histórias" com mais "clicks", mais comentadas ou partilhadas. 0 que significa que temos um fenómeno novo, de redução significativa da diversidade e do pluralismo num contexto que já de si, em termos de media mainstream, era extremamente deficitário em particular em matéria de pluralidade das vozes.

\section{As PRIMEIRAS ABORDAGENS}

Importa então pensar este novo fenómeno no atual contexto de migração para o digital, procurando estruturar um conjunto de referências, documentos, relatórios e legislação, que nos permita ter uma visão mais alargada e consistente de como esta questão está a ser observada pelos sistemas de governo e de regulação e por entidades independentes, pela academia, centros de investigação, etc. A questão da diversidade e do pluralismo é, do nosso ponto de vista, absolutamente crucial para o sistema de media neste momento muito crítico para o seu futuro. Vejamos então, mais em particular, o que se tem passado fundamentalmente com o sistema regulatório no âmbito da experiência dos media públicos nacionais.

Em Portugal, até à data, a ERC desenvolveu apenas um estudo no âmbito específico da diversidade. Esse estudo foi feito no ano de 2008, apresentado em 2009 e divulgado no site da ERC em janeiro de 2011.0 estudo "Imigração e diversidade étnica, linguística, religiosa e cultural na imprensa e televisão" analisava fundamentalmente a cobertura mediática de temas e protagonistas associados à imigração e diversidade étnica, linguística, religiosa e cultural. Coordenado por Isabel Ferin e publicado em 2011 pela ERC, teve ainda o patrocínio do Alto Comissariado para a Imigração e Diálogo Intercultural (ACIDI). 0 estudo dá ainda continuidade a três outros estudos anteriores, genericamente sobre Media, Migração e Minorias Étnicas, publicados entre 2004 e 2007, então patrocinados pelo ACIME (Alto Comissariado para a Imigração e Minorias Étnicas), e realizados no âmbito do Observatório da Imigração.

Este estudo começa por referir a criação do European Monitoring Centre on Racism and Xenophobia (EUMC), em Junho de 1997, como um momento relevante nas políticas europeias para os Media e Diversidade ao longo de cerca de dez anos, sobretudo pelo reportado nos relatórios da instituição e da rede Raxen, um centro europeu de informação sobre o racismo e a xenofobia. 0 papel determinante dos media neste âmbito da diversidade era aí claramente exposto embora posteriormente as atribuições do centro tivessem sido integradas na Agência dos Direitos Fundamentais da União Europeia.

Refira-se, em todo o caso, que desde o Livro Verde do audiovisual europeu, de 1984, seguido da Diretiva Televisão Sem Fronteiras (1989), com todas as suas atualizações posteriores (1997, 2007 e 2010) as temáticas dos direitos das minorias bem 
como os princípios da diversidade e do pluralismo eram já um pressuposto plenamente adquirido no espírito da lei, sendo replicados depois nas diferentes legislações dos Estados-membros.

No texto da Diretiva' ${ }^{\prime}$ os temas da diversidade e do pluralismo são uma constante. Veja-se, por exemplo, logo no considerando $n^{0} 6$ :

"O n. ${ }^{\circ} 4$ do artigo $167 .{ }^{\circ}$ do Tratado sobre o Funcionamento da União Europeia dispõe que, na sua ação ao abrigo de outras disposições desse Tratado, a União deve ter em conta os aspetos culturais, a fim de, nomeadamente, respeitar e promover a diversidade das suas culturas."

Ou o considerando $n^{0} 12$, que diz o seguinte:

"(...) a política de regulação no sector tem de salvaguardar um conjunto de interesses públicos, tais como a diversidade cultural, o direito à informação, 0 pluralismo dos meios de comunicação social, a proteção dos menores e a defesa dos consumidores, e reforçar a capacidade crítica do público e a educação para os media, agora e no futuro."

\section{0 QUADRO LEGAL PORTUGUÊS}

0 quadro legal na área dos media em Portugal está, aliás, bem documentado em matéria de liberdade de informação. 0 Artigo 37. ${ }^{\circ}$ da Constituição - "Liberdade de expressão e informação", diz, no seu n ${ }^{0} 1$, que "Todos têm o direito de exprimir e divulgar livremente o seu pensamento pela palavra, pela imagem ou por qualquer outro meio, bem como o direito de informar, de se informar e de ser informados, sem impedimentos nem discriminações". No seu $n^{0} 2$, a lei fundamental da República Portuguesa prescreve que "o exercício destes direitos não pode ser impedido ou limitado por qualquer tipo ou forma de censura". Deve ainda referir-se o Artigo 13. "Princípio da igualdade", $\mathrm{n}^{0}$ 1: "Todos os cidadãos têm a mesma dignidade social e são iguais perante a lei". E ainda $0 \mathrm{n}^{0}$ 2: "Ninguém pode ser privilegiado, beneficiado, prejudicado, privado de qualquer direito ou isento de qualquer dever em razão de ascendência, sexo, raça, língua, território de origem, religião, convicções políticas ou ideológicas, instrução, situação económica, condição social ou orientação sexual."

Também o Estatuto do Jornalista impõe como deveres fundamentais dos jornalistas, independentemente do disposto no respetivo código deontológico, e designadamente no seu artigo 14, $n^{0}$ 2, alínea e), relembrando 0 artigo 13 da Constituição: "Não tratar discriminatoriamente as pessoas, designadamente em razão da ascendência, sexo, raça, língua, território de origem, religião, convicções políticas ou ideológicas, instrução, situação económica, condição social ou orientação sexual". E como bem refere o estudo de Isabel Ferin, importa ainda citar a lei da Televisão e o Contrato de Concessão do Serviço Público de Televisão, dado que este

1 Diretiva 2010/13/UE do Parlamento Europeu e do Conselho, de 10 de março de 2010, relativa à coordenação de certas disposições legislativas, regulamentares e administrativas dos Estados-Membros respeitantes à oferta de serviços de comunicação social audiovisual (Diretiva «Serviços de Comunicação Social Audiovisual»). 
quadro regulatório, em particular, especifica as questões fundamentais relativas designadamente ao operador público de televisão para o cumprimento de atribuições e competências em matéria de pluralismo e diversidade.

Questão, aliás, evidente nos próprios considerandos do Contrato de Concessão, designadamente nos parágrafos $(X),(Y)$ e (Z):

Que a Convenção sobre a Proteção e a Promoção da Diversidade das Expressões Culturais, adotada pela 33. ${ }^{\text {a }}$ sessão da Conferência Geral da UNESCO, em Paris, a 20 de outubro de 2005, aprovada pela Resolução da Assembleia da República n. ${ }^{0} 10-\mathrm{A} / 2007$, de 16 de março e ratificada pelo Decreto do Presidente da República n. ${ }^{0} 27-B / 2007$, da mesma data, reconhece que as Partes detêm o direito soberano de adotar políticas e medidas para proteger e promover a diversidade das expressões culturais dentro do seu território, entre as quais as destinadas a estimular a diversidade dos meios de comunicação social, incluindo através do serviço público de radiodifusão;

Que, pela mesma Convenção, é reconhecido o papel fundamental da sociedade civil na proteção e na promoção da diversidade das expressões culturais;

Que a Recomendação Rec (2007) 3 do Comité de Ministros do Conselho da Europa, reconhecendo que a missão do serviço público de radiodifusão, num contexto de globalização e integração internacional, bem como de crescente concentração dos média privados e de rápida mudança dos padrões de consumo e nível de expectativas do público em matéria de conteúdos de comunicação, assume ainda maior relevância, devendo também ser prosseguida através de novas plataformas e serviços de comunicação social, de modo a otimizar o seu potencial e especialmente a promover uma maior participação democrática, social e cultural.

Refira-se ainda, entre outros aspetos, a questão da relação do media com 0 ambiente societal, onde se diz que o serviço público deve constituir-se "como um fator de coesão e integração de todos os indivíduos, grupos e comunidades sociais" (...). Nesta perspetiva, o serviço público deve, nomeadamente (parágrafo BB):

"(...) Disseminar conteúdos audiovisuais inovadores e diversificados, de acordo com padrões éticos e qualitativos elevados, e assumir-se como um fórum de discussão plural e meio de promover a participação democrática alargada dos cidadãos, bem como e contribuir para a criação e produção audiovisual, assegurando a divulgação da diversidade da herança cultural nacional e europeia".

Ainda em matéria de Contrato de Concessão, refira-se a Cláusula 6. ${ }^{\text {a }}$ - Obrigações Específicas da Concessionária, no seu n ${ }^{0} 2$, que considera que à concessionária incumbe, designadamente: a) "Fornecer uma programação variada e abrangente, que promova a diversidade cultural e tenha em conta os interesses das minorias". E a Cláusula 16. ${ }^{a}$ - Ações a Desenvolver em Matéria de Programação: f) "Promover, nas emissões dirigidas às comunidades africanas, acontecimentos e iniciativas que, pela sua importância e qualidade, reflitam a riqueza e diversidade cultural daquelas comunidades". 
Por fim veja-se que a própria Lei da Televisão (Lei da Televisão e dos Serviços Audiovisuais a Pedido - Lei n. ${ }^{0}$ 27/2007, de 30 de julho) ${ }^{2}$ começa por considerar genericamente que constituem obrigações gerais de todos os operadores de televisão "assegurar, incluindo nos horários de maior audiência, a difusão de uma programação diversificada e plural" ${ }^{3}$ Mas no que concerne em particular o Serviço Público de Televisão, diz o Artigo 51. ${ }^{\circ}$ - Obrigações específicas da concessionária do serviço público de televisão, no seu n 1, que "a concessionária do serviço público de televisão deve (...) apresentar uma programação que promova a formação cultural e cívica dos telespectadores, garantindo 0 acesso de todos à informação, à educação e ao entretenimento de qualidade". E no seu n ${ }^{0} 2$, diz - replicado no Contrato de Concessão - que "à concessionária incumbe, designadamente: a) Fornecer uma programação variada e abrangente, que promova a diversidade cultural e tenha em conta os interesses das minorias". Este artigo refere ainda várias outras obrigações afins, dentro das temáticas específicas da missão do serviço público de televisão, mas não faz qualquer discriminação entre os dois canais generalistas, assumindo-se que ambos têm as mesmas atribuições e competências expressas no clausulado.

Há, no entanto, uma diferenciação de competências, designadamente no Artigo 53. ${ }^{\circ}$-Primeiro serviço de programas generalista de âmbito nacional; e no Artigo $54^{\circ}$ - Segundo serviço de programas generalista de âmbito nacional. Se no primeiro 0 legislador considera que este deve ser "dirigido ao grande público" embora devendo transmitir, por exemplo, "programas de carácter cultural" ou "conceder especial relevo" à "sensibilização dos telespectadores para os seus direitos e deveres enquanto cidadãos", já no Artigo 54 ", vem considerar que o segundo serviço de programas "compreende uma programação de forte componente cultural e formativa", devendo "assegurar uma programação de grande qualidade, coerente e distinta dos demais serviços de programas televisivos de serviço público". A lei contradiz-se assim a si própria e subverte o princípio e a missão do serviço público ao exigir que um dos canais - o segundo - assuma os "custos" culturais do serviço, que conferem o princípio e a existência legal à concessionária, como que permitindo uma descaracterização do principal canal do sistema público através do mimetismo dos privados e do entretenimento "light", em suma, legitimando a "ditadura da audiência" e a concorrência desleal do próprio operador público.

\section{INICIATIVAS E ESTUdOS NACIONAIS E EUROPEUS}

Múltiplas iniciativas europeias, institucionais ou não, outras ainda no plano da cidadania, foram então desenvolvidas nesta matéria sobretudo desde os anos 90 do século passado. No caso português citem-se de facto as múltiplas iniciativas do ACIME e do ACIDI, no sentido de implementar estudos e estratégias de comunicação para a sensibilização dos media, dos jornalistas e da própria opinião pública para os temas da imigração, dos refugiados e da diversidade cultural. Ou mesmo o magazine televisivo NÓS, da RTP, sobre a imigração e a diversidade cultural em Portugal, ou o Programa Escolhas, do ACIDI, com a participação de muitas outras

2 Alterada pela Lei n. ${ }^{0} 8 / 2011$, de 11 de abril, pela Lei n. ${ }^{0}$ 40/2014, de 9 de julho, e pela Lei n. ${ }^{0}$ 78/2015, de 29 de julho), artigo $34 .{ }^{\circ}$, n. $^{0}$ 2, alínea a).

3 Lei da Televisão, $n^{0} 7 / 2007$, Artigo $34^{\circ}$ - Obrigações gerais dos operadores de televisão, $n^{0} 2$-a) 
entidades, destinado fundamentalmente a aprofundar contextos de diversidade e apoiar a inclusão dos jovens na sociedade portuguesa.

Refira-se, no entanto, uma situação muito particular, que não abona em nada aquilo que se poderá considerar a atenção particular das políticas públicas europeias em matéria de diversidade. Um dos programas de apoio a estas políticas - 0 programa MEDIANE - Media in Europe for Diversity Inclusiveness ${ }^{4}$, uma iniciativa conjunta da União Europeia e do Conselho da Europa, nos anos 2013-2014, terá tido um fim inglório, depois do encontro de Lisboa, em março de 2014, onde se procurava avançar num sistema de acompanhamento designado por Monitoring and Action Box on Media Diversity Inclusiveness. 0 programa tinha objetivos ambiciosos, propunha-se encorajar a disseminação de conteúdos, design e produção de informação verdadeiramente inclusiva:

"Tendo como base as várias recomendações dos órgãos do Conselho da Europa sobre o pluralismo dos media e a expressão da diversidade, bem como os sucessos da campanha anti discriminação de 2008-2010 e ainda o seu programa conjunto com a UE, MARS - Media contra o Racismo no Desporto, o programa MEDIANE visa fazer da diversidade e da não discriminação os prismas permanentes da cobertura mediática".

Basicamente o MEDIANE tinha como objetivo final "facilitar o estabelecimento de uma rede entre os parceiros mediáticos europeus e os atores relevantes tendo como interesse partilhado a promoção de modos mais inclusivos de produção mediática e jornalística". Infelizmente deste programa não mais se ouviu falar, o que naturalmente se lamenta dada a ambição do programa e a sua evidente relevância no contexto destas temáticas no contexto europeu.

Voltando às conclusões do estudo coordenado por Isabel Ferin, intitulado, como referimos, "Imigração, diversidade étnica, linguística, religiosa e cultural na Imprensa e na Televisão". Tal como enunciado, a comparação do ano de 2008 com os estudos realizados nos anos anteriores, mantém, genericamente, o "padrão de cobertura", isto é, os acontecimentos associados ao crime "marcam os picos de agendamento, dando visibilidade à Imigração e às designadas minorias e provocando 0 aumento do número de peças nos meios de comunicação" ${ }^{5}$

Na televisão as temáticas da transgressão social e do crime são as que dominam, sendo que os interlocutores privilegiados nas notícias são as forças de segurança, enquanto as $0 \mathrm{NG}^{\prime}$ s, associações de imigrantes ou de comunidades ciganas, por exemplo, surgem com menor representação, de acordo com as conclusões do estudo.

Outra conclusão que não deixava de ser preocupante era a seguinte: "Nos canais generalistas de televisão verifica-se que é nos jornais televisivos que se regista menos diversidade e pluralismo na informação, encontrando-se estas características

4 Ver a informação disponibilizada na altura sobre o MEDIANE no website do Conselho da Europa: http://www.coe.int/t/dg4/cultureheritage/mars/mediane/default_en.asp

http://www.coe.int/t/dg4/cultureheritage/mars/mediane/source/encounters/portugal/03-MEDIANE-Portugal-Agenda_PR.pdf (acedido em 8 de novembro de 2016).

5 Imigração, diversidade étnica, linguística, religiosa e cultural na Imprensa e na Televisão, p. 124. 
presentes em todos os canais, nomeadamente no operador público" ${ }^{6}$ De uma maneira geral, os telejornais da informação televisiva diária "privilegiavam o espetáculo e a informação superficial", enquanto que nos não-diários se promovia de forma mais consistente "o aprofundamento dos temas e a informação contextualizada". Da mesma forma, verificava-se "uma tendência para enfatizar as 'bad news' sobre a Imigração, diversidade étnica, linguística, religiosa e cultural".

Por fim, e não menos importante, anote-se o seguinte: "Os operadores de televisão, tanto o público (RTP) como os privados (SIC e TVI), tendem a não contemplar, na sua programação, os interesses gerais e diversificados dos cidadãos, não assegurando uma informação plural que contribua para a formação cívica dos espectadores". 0 estudo acaba por concluir que

"O princípio da seleção é a procura do sensacional, do espetacular. A televisão apela à dramatização, no duplo sentido da palavra: põe em cena, em imagens, um acontecimento e exagera a sua importância, a sua gravidade e o seu carácter dramático, trágico. (...). Em outros estudos sobre televisão, sobre outros temas e com outros corpora de análise, já foram apontados os mesmos procedimentos de rotina, que envolvem as mesmas estratégias de espectacularização de acontecimentos e a sistemática utilização de fontes oficiais." ${ }^{7}$

\section{A diversidade do SPT nO CONTEXTO REgulatóRio}

Na nossa observação das grelhas de programação dos canais generalistas do serviço público de televisão são identificados regularmente, nos vários dias e/ou semanas estudados, vários problemas associados em particular à questão da diversidade da oferta, nomeadamente no plano da diversidade de géneros televisivos e de oferta de programas no âmbito do conhecimento e da cultura, em particular na RTP1. Vamo-nos deter mais especificamente no âmbito da oferta de programas em geral, excetuando a informação diária, que, pela sua especificidade, nos merecerá uma análise posterior, ainda que pudessem ser referidos dados, em particular no âmbito do pluralismo político, com base nos Relatórios específicos da ERC sobre pluralismo político-partidário da informação televisiva.

Refira-se que, ainda no âmbito dos estudos da ERC, o essencial da sua abordagem prende-se com a matéria político-partidária, tal como observado já por Elsa Costa e Silva: "Da sua atividade de monitorização sobressai a atenção dada à política partidária e formal e, nos mecanismos que disponibiliza à sociedade, encontramos a presença esmagadora dos mesmos atores. Vozes alternativas, críticas ou não oficiais não aparecem, desta forma, representadas nas análises ao pluralismo efetuadas pela entidade reguladora" (2013: 113).

Mas a diferenciação de perfil ou a dita "complementaridade" entre os dois canais generalistas da RTP é um problema recorrente no serviço público de televisão, nunca suficientemente discutido. Basta olharmos, por exemplo, para a Deliberação da ERC 2016/85, que procura verificar a boa execução dos contratos de concessão da empresa, para se perceber que este é um tema de grande relevância.

6 Op. cit., p. 127.

7 Idem, p. 128. 
No documento, a ERC cita o seu próprio Relatório de Regulação do ano de 2013 - referente ao ano em apreciação na auditoria - para dizer que, quanto à RTP1 e no que diz respeito, nomeadamente, à diversidade das categorias de programas das grelhas de programação "manteve-se a predominância registada em 2012, de três categorias, a saber, informativos, ficção e entretenimento, assinalando-se, novamente, pela negativa a irrelevância dos conteúdos infantis/juvenis" .80 regulador identifica aliás, de modo positivo, o crescimento da oferta televisiva em matéria de promoção da diversidade cultural e de grupos minoritários, assinalando o "acréscimo de programas exibidos", concluindo que em referência a 2013 "a programação da RTP1 dirigida a grupos minoritários tornou-se uma das que revela a complementaridade entre os dois serviços de programas do operador público de televisão (...)".

Quanto à RTP2, constata que nesse ano, em 2013, se verificou uma alteração significativa, com "um aumento muito relevante da programação informativa, em detrimento da de cultura e conhecimento". Em matéria de programação infantil/juvenil, a RTP2 mantinha a tendência dos últimos anos, e continuou a ser "o serviço que mais programação destinou às faixas etárias mais jovens, destacando-se os géneros desenhos animados e educativos infantis/juvenis", aqui sobretudo em oposição à referida "irrelevância" dos conteúdos infantis/juvenis do principal canal do operador público.

Aliás, nesta matéria - e bem - a ERC insta a concessionária, para que, nomeadamente na RTP1, a programação infantil "possa ter maior relevo, não assumindo que pelo simples facto de a RTP2 incluir em moldes mais significativos este género de formato na sua programação, isso será suficiente para desonerar a RTP1 da disponibilização deste tipo de conteúdos". ${ }^{9}$

Vejam-se finalmente os pontos 3 e 4 da Deliberação propriamente dita (85/2016 - Cap. V $)^{10}$, e repare-se que, muito embora se trate aqui, nesta auditoria, de matéria essencialmente referente aos fluxos financeiros associados à execução do Contrato de Concessão, a verdade é que a matéria referente à programaç̧ão não deixa de estar presente de forma muito clara:

"3. 0 Conselho Regulador, face às conclusões da auditoria e do Relatório de Regulação, sublinha a necessidade de o operador de serviço público assegurar a diversidade de oferta de géneros programáticos a que está contratual e legalmente obrigado, nomeadamente ao nível dos programas infantis/juvenis e culturais/ conhecimento, reiterando-se aqui o alerta já anteriormente efetuado (referência à Deliberação 5/0UT-TV/2012, de 27 de junho de 2012, relativa à Auditoria referente a 2010), quanto à 'necessidade de o operador de serviço público equilibrar a diversidade da oferta televisiva em ambos os serviços de programas, encarando a complementaridade, não como um seccionamento de géneros, por serviço de programas, mas antes como o equilíbrio quantitativo de conteúdos de cada género em cada um dos serviços de programas' ".

8 Deliberação ERC/2016/85(OUT-TV). Auditoria à empresa concessionária do serviço público de televisão, RTP - Rádio e Televisão de Portugal, S.A., referente ao ano de 2013, pág. 7. ERC, 13 de abril de 2016.

9 Op. cit., p. 15.

10 Idem, pág. 16. 
“4. Recomenda-se à Rádio e Televisão de Portugal, S.A., a contínua melhoria e escrupuloso cumprimento das obrigações contratuais de diversidade de programação em todos os seus serviços de programas, bem como o respeito pela garantia de acesso de públicos com necessidades especiais a todos os programas e em particular os dos géneros ficção e documentários."

Esta temática tem a sua mais recente atualização no Relatório de Regulação de 2015 adotado pelo Conselho Regulador da ERC, de julho de 2016. Mais especificamente em matéria de Pluralismo e Diversidade nos serviços de programas televisivos do Serviço Público, a análise de programação dos canais generalistas foi a seguinte:

Quanto à RTP1 (p. 29 - Vol. 1), em 2015 o volume horário da RTP1 foi de 7005h11 m57s. No ano de 2015, predominam os programas de entretenimento, atingindo $33,6 \%$ da duração. Seguem-se os programas informativos $(31,1 \%)$ e a ficção $(23,3 \%)$.

A RTP1 emitiu 389 horas de programas culturais/conhecimento em 2015, resultantes de 1240 edições, repartidos por sete géneros. Estes correspondem às diversas exigências estabelecidas pelo CCSPRT para o primeiro serviço de programas do operador de serviço público de televisão.

Com 112 horas, 0 Documentário é o género que atinge maior relevo temporal, preenchendo $28,9 \%$ do conjunto. Os programas de informação cultural surgem de seguida $(23,7 \%)$, bem como os espetáculos $(18,8 \%)$ e os programas de humanidades $(14,8 \%)$.

A RTP1 exibiu em 2015 apenas 39 programas destinados à promoção da diversidade cultural e dos interesses de grupos minoritários, que cobrem os géneros informação cultural, educativo e religioso.

Por sua vez, os programas de cariz institucional/religioso são os menos expressivos nas grelhas de emissão da RTP1 em 2015, com 103 horas de emissão global (1,5\%), seguindo-se os conteúdos infantis/juvenis, com 153 horas de emissão (2,2\%).

Quanto à RTP2, em 2015 o volume horário da RTP2 foi de: 8400h39m29s. A RTP2, segundo este relatório da ERC (p. 30 - Vol. 1), é "o serviço de programas generalista português de acesso não condicionado livre que destina o maior número de horas de emissão aos seus públicos, com a equivalente maior oferta de conteúdos programáticos do panorama nacional". Note-se que a RTP2 tem uma oferta "exígua de conteúdos pertencentes ao macrogénero entretenimento (meio ponto percentual das horas totais da programação de 2015)".

Em 2015 regista então um total de horas de emissão superior à RTP1, resultantes da exibição de 20518 programas. Nas grelhas de emissão o destaque horário cabe aos informativos (36,2\%), aos infantis/juvenis (28,3\%) e aos culturais/conhecimento $(18,3 \%)$, que agregados, segundo o relatório, totalizam mais de quatro quintos $(82,8 \%)$ da duração global de emissão da RTP2.

Para além dos informativos, que ocupam o primeiro lugar em total de horas de emissão, o destaque principal da grelha vai efetivamente para os infantis/juvenis. Neste âmbito, destacam-se os géneros desenho animado, na segunda posição, com $14,8 \%$, sendo que 0 outro género de programas para os mais novos mais regular é 0 "educativo infantil/juvenil", que é o segundo mais frequente em termos de exibição (14 \%). Tal como diz este relatório da ERC: 
"Prosseguindo a sua vocação de serviço de programas orientado para os mais novos, a RTP2 foi o serviço de programas generalista de sinal aberto que destinou mais programação às faixas etárias mais jovens em resultado da emissão de 2376h19m08s de conteúdos infanto-juvenis, resultantes da emissão de 11915 programas".

Repare-se ainda, relativamente ao âmbito dos programas culturais propriamente ditos, que a RTP2 apresenta um valor muito significativo neste âmbito, o que explicita claramente o perfil deste canal no contexto da oferta do serviço público (p. 31):

"A cultura e o conhecimento também tiveram lugar de destaque nas greIhas de emissão da RTP2. Em 2015, o canal difundiu 3868 programas identificados como pertencendo à categoria cultural/conhecimento, 0 correspondente a $1538 \mathrm{~h} 22 \mathrm{~m} 18 \mathrm{~s}$ de emissão anual distribuídas por sete géneros. A mais longa duração dos documentários face aos outros géneros da categoria cultural/conhecimento torna-os prevalecentes no indicador duração, em que valem um terço do tempo total de emissão (34\%). Metade do tempo destes cabe aos programas classificados de humanidades $(17,2 \%)$, seguidos de perto dos de artes e media $(15,3 \%)$ e os espetáculos $(14,6 \%)$.

Finalmente, refira-se que a RTP2 tem também um posicionamento relevante no âmbito dos "conteúdos vocacionados para os grupos minoritários e a promoção da diversidade social e cultural, com 586 exibições, 0 equivalente a 274h02m51s de emissão", o que equivale a uma quota não muito alta, mas que de qualquer modo deve ser anotada e perspetivada em termos do seu potencial de crescimento dado o perfil do canal: 3,2\% na programação de 2015 .

No Volume 2 do mesmo Relatório de Regulação de 2015, de julho de 2016 ${ }^{11}$, é desenvolvida uma análise mais fina no contexto dos programas de "diversidade", considerada aqui como "uma das dimensões de pluralismo - entendido em sentido lato, enquanto representação de um vasto conjunto de valores, opiniões, informações e interesses sociais, políticos e culturais" (p. 8). A metodologia do estudo propõe que uma das formas de aferir essa dimensão seja a "identificação dos géneros televisivos a que correspondem os conteúdos selecionados pelos operadores para integrar as suas grelhas de emissão diárias" (id.), o que não nos parece poder ir verdadeiramente ao âmago da questão, isto é, à plena identificação e especificidade, em matéria de diversidade, dos conteúdos propriamente ditos. A própria tipificação feita do conceito de diversidade também nos parece extremamente pobre e insuficiente. A conclusão desta abordagem surge mais à frente no Relatório da ERC, de forma, portanto, insatisfatória, e onde se diz que (p. 12):

"De um modo geral, em 2015, a RTP1 cumpre as obrigações de diversidade que the são impostas pelos normativos destacados (...), nomeadamente por se verificar que as suas grelhas anuais de programação contemplam conteúdos perten-

11 ERC (2016). Relatório de Regulação de 2015. Vol. 2. http://www.erc.pt/documentos/ Relatorios/ERC_Relatorio_de_Regulacao_2015_Volume2/ERC_RR_2015_Vol_2_web/assets/downloads/ERC_Relatorio_de_Regulacao_2015_Volume2.pdf 
centes aos sete macrogéneros em análise, subdivididos em 33 géneros televisivos de entre os 39 considerados."

Importaria aqui que a ERC densificasse o conceito e procedesse a uma análise complementar de conteúdo, com uma avaliação essencialmente qualitativa, procurando abarcar as múltiplas dimensões do conceito ${ }^{12}$, a saber, nomeadamente: a diversidade cultural, étnica e linguística; o conteúdo intercultural, o multiculturalismo; a pluralidade das expressões e vozes. As questões da juventude; exclusão/inclusão sociocultural, subculturas juvenis; género e discriminação. Conteúdos e acessibilidade para pessoas com necessidades especiais, idosos, experiências de envelhecimento. Proteção do património e da cultura nacional/local. E por fim a questão da diversidade de géneros de programação televisiva.

Ora, em 2015, segundo o Relatório da ERC, a RTP1 emitiu 46 espetáculos, nomeadamente (p.38): tauromaquia e marchas populares; Rui Veloso: 25 anos; Tony Carreira: 25 anos; Silence 4: songbook live 2014". E escreve ainda o seguinte (p.38): "No âmbito performativo, refira-se a emissão de "Grande Revista à Portuguesa" e "Grande Noite do Fado Lisboa 2006" e "Grande noite do Fado Porto 2006", em contraponto com a ausência de espetáculos de ópera e bailado, entre outras encenações de natureza mais erudita." Ora, associar aqui o fado a espetáculo performativo causa uma certa perplexidade, conviria claramente rever esta metodologia e tipificar melhor os conceitos para evitar erros deste tipo.

Finalmente, no âmbito da "promoção da diversidade cultural" e no que se refere ainda aos "interesses de grupos minoritários" (p.45), são três os programas identificados: "Músicas D’África" e os programas de edição única, "Peregrinação Internacional do Migrante" e "Vivo em Portugal". Conclui o relatório que "face ao ano anterior, verifica-se deste modo uma acentuada diminuição do número de edições anuais de programas para públicos minoritários: de 234 para 39, com um recuo de 127 h 11 h 18 m para 36 h 54 m 48 s."

No que respeita à RTP2, refira-se desde já que a esta compete integrar na sua programação, segundo o Contrato de Concessão da RTP, uma oferta cultural "distinta dos demais serviços de programas televisivos de serviço público"13 e, ainda, segundo o mesmo contrato (cláusula 10. ${ }^{a}, n^{0}{ }^{3}$ ) constituir-se como "uma alternativa à oferta da RTP1, bem como às ofertas de programação cultural do mercado".

\section{Reflexões finais}

Nesta medida, faz todo o sentido que a programação da RTP2 satisfaça "as obrigações gerais de diversidade e de pluralismo". Na sequência, o Relatório afiança ainda que as grelhas de emissão da RTP2 de 2015 "contemplam conteúdos pertencentes aos sete macrogéneros considerados na análise, que se desdobram em 30

12 Estas são as dimensões utilizadas no âmbito do projeto FCT que temos em curso: DIVinTV Televisão pública e diversidade cultural em Portugal: um estudo sobre a programação dos canais públicos generalistas, em matéria de pluralidade de expressão cultural, diversidade e inclusão (PTDC) IVC-COM/4968/2014).

13 Contrato de Concessão do Serviço Público de Rádio e de Televisão, 6 de março de 2015, cláusula $10 .{ }^{a},{ }^{0}{ }^{0} 2$. 
géneros televisivos, assim respondendo às obrigações específicas de programação" (p. 15), frase que por si só não tem significância.

É nesta lógica que surge, por assim dizer, a "menorização" da missão da RTP1, dado que o Contrato de Concessão confere à partida a ilibação do principal canal de serviço público relativamente às opções centrais de prestação do serviço público, deslocando-as em peso para a RTP2. Assim sucede também nas referências, por exemplo, à igualdade de género, à divulgação de causas humanitárias, ao desporto amador e ao desporto escolar, às confissões religiosas, ao ambiente e à defesa do consumidor, aos espaços educativos destinados ao público infantojuvenil e que contribuam para a sua formação, etc., etc.

Uma conclusão que podemos retirar desta avaliação constante do Relatório de Regulação da ERC de 2015 é assim a de que o facto de a RTP2 surgir com uma estratégia de programação complementar da RTP1, permite compensar, pela ausência de conteúdo, o infrator, melhor dito, o principal canal do serviço púbico num âmbito que é justamente uma das prerrogativas da sua missão. Ou seja, uma das atribuições e competências determinantes na oferta do serviço público, e indistintamente - se é que o conceito é (deve ser) de facto indivisível e não manipulável - é a inclusão de conteúdos e programas específicos em matéria de infantis/juvenis, cultura e conhecimento, promoção da diversidade social e cultural e ainda de programas em matéria de visibilidade dos grupos minoritários, como inclusive sucede com a insuspeita BBC ${ }^{14}$. Para além disso, como refere Horsti (2014: 56) em matéria de diversidade cultural não são feitos grandes esforços no audiovisual europeu para encontrar soluções capazes de conter os novos tipos de racismo e discriminação que estão a regressar à Europa.

Ora, sendo estas as áreas onde mais se afirma a dimensão do serviço público de televisão no âmbito específico da "missão", são justamente estas as áreas em que a RTP1 menos intervém e menos explicita as suas atribuições e competências, o que, do nosso ponto de vista, afeta, e em última instância põe em perigo a própria questão do financiamento público, ou seja, coloca em causa a sua própria legitimação e presença no contexto da oferta de serviço público.

Outro tópico crítico é o da difusão de programas de origem europeia. De acordo com a Diretiva europeia e a Lei da Televisão (Artigo 45) os operadores de televisão devem incorporar uma percentagem maioritária de obras europeias na programação dos seus serviços, uma vez deduzido o tempo dedicado aos noticiários, manifestações desportivas, concursos, publicidade, televenda e teletexto. A questão, aliás dramática para a experiência televisiva europeia das últimas décadas (com impactos profundos na atual crise de coesão da UE) ${ }^{15}$, é que os Estados-membros convencionaram, à revelia do espírito inicial da Diretiva - que procurava essencialmente combater o domínio completo dos écrans europeus pelo audiovisual norte-americano -, que a produção nacional em cada país deve contribuir já para a quota

14 A Future for Public Service Television: Content and Platforms in a Digital World. A report on the future of public service television in the UK in the 21st century. Goldsmiths - University of London, 2016.

15 Cádima, F. Rui (2016). "Da TV pública europeia à 'alienação' da Ideia de Europa". Intercom: Revista Brasileira de Ciências da Comunicação, 39(2), 39-47. http://www.scielo.br/pdf/interc/ v39n2/1809-5844-interc-39-02-0039.pdf 
de "produção europeia", pelo que se assiste hoje - e, no fundo, desde sempre - a um completo deserto de produção europeia dos países terceiros nos écrans dos diferentes países, incluindo nos canais de serviço público dos Estados-Membros, naturalmente com maior gravidade neste caso.

\section{REFERÊNCIAS BIBLIOGRÁFICAS}

A Future for Public Service Television: Content and Platforms in a Digital World (2016). A report on the future of public service television in the UK in the 21st century. Goldsmiths - University of London.

Cádima, F. R. (2016). Da TV pública europeia à 'alienação' da Ideia de Europa. Intercom: Revista Brasileira de Ciências da Comunicação, 39(2): 39-47. URL: http://www.scielo.br/ pdf/interc/v39n2/1809-5844-interc-39-02-0039.pdf.

Cádima, F. R. (2016a). 0 Public Service Media, a RTP e os Desafios da Era Digital. Actas do II Congresso Internacional de Comunicação, Jornalismo e Espaço Público, sobre os Desafios dos Media de Serviço Público. Organização: Universidade de Coimbra. № 2 da revista Mediapolis, 2016, pp. 63-71. https://digitalis-dsp.uc.pt/bitstream/10316.2/39187/1/0\%20Public\%20Service\%20Media\%20a\%20RTP\%20e\%20os\%20desafios\%20da\%20era\%20digital.pdf?!n=es

Constituição da República Portuguesa (2005). VII Revisão Constitucional. http://www.parlamento.pt/Legislacao/Paginas/ConstituicaoRepublicaPortuguesa.aspx.

Contrato de Concessão do Serviço Público de Rádio e Televisão (2015). http://media.rtp.pt/ empresa/wp-content/uploads/sites/31/2015/07/contratoConcessa02015.pdf.

Deliberação ERC/2016/85(OUT-TV). Auditoria à empresa concessionária do serviço público de televisão, RTP - Rádio e Televisão de Portugal, S.A., referente ao ano de 2013. ERC, 13 de abril de 2016.

Diretiva 2010/13/EU (Diretiva «Serviços de Comunicação Social Audiovisual») do Parlamento Europeu e do Conselho, de 10 de março de 2010. http://eur-lex.europa.eu/LexUriServ/ LexUriServ.do?uri=0J:L:2010:095:0001:0024:pt:PDF.

ERC (2016). Relatório de Regulação, Vol 1 e 2. http://www.erc.pt/pt/estudos-e-publicacoes/ relatorios-de-regulacao/relatorio-de-regulacao-2015.

ERC (2016a). Relatório de Acompanhamento da Observância do Pluralismo Político - Informação Televisiva Diária e Não Diária - 2015. http://www.erc.pt/pt/estudos-e-publicacoes/relatorios-do-pluralismo-politico-partidario/relatorio-de-acompanhamento-da-observancia-do-principio-do-pluralismo-politico-em-2015.

Ferin, I. (2011). Imigração e diversidade étnica, linguística, religiosa e cultural na imprensa e televisão. http://www.erc.pt/pt/estudos-e-publicacoes/diversidade/imigracao-e-diversidade-etnica-linguistica-religiosa-e-cultural-na-imprensa-e-televisao-2008.

Hargrave, A. M. (2007) (ed). Cultural Diversity Practices among Broadcasting Regulators. Barcelona/CAC: Broadcasting Regulation and Cultural Diversity Network.

Horsti, K. (2014). The Cultural Diversity Turn: Policies, Politics and Influences at the European Level. In G. Titley, K. Horsti, \& G. Hultén (Eds.), National Conversations - Public Service Media and Cultural Diversity in Europe (pp. 43-60). Bristol: Intellect Itd.

Lei da Televisão e dos Serviços Audiovisuais a Pedido (2007). Lei n. ${ }^{0} 27$, de 30 de Julho. https://dre.pt/application/dir/pdf1sdip/2007/07/14500/0484704865.pdf. 
Livro Verde (1984) relativo ao estabelecimento do mercado comum da radiodifusão [COM(84) 300 final]. CEE, Bruxelas.

MEDIANE - Media in Europe for Diversity Inclusiveness (2014). Council of Europe. http:// www.coe.int/t/dg4/cultureheritage/mars/mediane/default_en.asp.

Silva, E. C. (2013). Regulando pluralismo e diversidade em Portugal: uma equação sem Cidadãos. Observatorio (OBS*) Journal 7(1): 101-117.

Silva, E. C.; Sousa, H. (2009). Diversidade no serviço público: um olhar sobre a RTP. Comunicación e Cidadania - Revista Internacional de Xornalismo Social 3: 233-248.

Francisco Rui Cádima - Professor Catedrático do Departamento de Ciências da Comunicação (FCSH/NOVA). Investigador Responsável do CIC.Digital.

Data de recepção do artigo/ Received for publication: 15.03.2017

Data de aceitação do artigo/ Accepted in revised form: 01.05.2017 